\title{
SUBPERIOSTEAL H丑MORRHAGE
}

\author{
(PROBABLY SCORBUTIC)
}

or

THREE LONG BONES IN A RICKETY INFANT.

\author{
BY \\ HeRberT W. PAGE, M.A., M.C. Cantab., F.R.C.S. Eng., \\ SURGEON TO \$T. MARY'S HOSPITAL.
}

Received January 29th-Read March 27th, 1883.

ON October 20th, 1882, a male infant, æt. 9 months, the first child of a young mother, was sent to me by $\mathrm{Dr}$. Taylor, of Willesden, under whose care it had been for a week, on account of great swelling of the left thigh and leg. The child was extremely wasted, pale, and ill, and was obviously in much pain. The mother gave the history that until four weeks ago the child was thriving, when a lump was noticed below the left knee. This lump had gradually grown larger and more extended, and the thigh also had become affected. There was no history of injury.

On examination the shafts of the tibia and femur were found to be, or gave the impression of being, enormously enlarged. The limb was excessively tender and motionless, but there was no redness, and the knee- and ankle- 
joints were not involved. There was a slight amount of œdema, and the superficial veins were unduly prominent. I failed to detect any certain fluctuation. For the last week a swelling had been noticed below the right knee also, and the upper third of the right tibia was found considerably swollen and tender, but without fluctuation. For the last few days a swelling had been seen at the right wrist, and there I found a typical rickety enlargement of the lower end of the radius. A like enlargement had been observed by Dr. Taylor at the lower end of the right tibia. The ribs were markedly though not extremely beaded. No other bones were in any way enlarged. Inquiring further into the history it was learned that the child immediately after birth was fed on Swiss milk, and that at the age of three weeks it was given Nestlé's milk food, on which and on Savory's food it had been reared up to this time, milk-Swiss milk-having been given in only very small quantities.

Looking to the condition of the wrist and the ribs, it seemed to me that the enlargement of the two tibiæ and of the femur must be in some way or other connected with rickets, but the absence of fluctuation rendered the nature of the swelling most obscure, and new growth appeared out of the question. An entire change in the mode of feeding was advised, but the child really seemed too ill to promise any hope of recovery. No history or suspicion even of syphilis could be elicited, but mercurial inunction was nevertheless suggested in addition to iron and cod-liver oil, treatment which had been already begun by Dr. Taylor.

On the following day the child came again, having, unknown to Dr. Taylor, been brought to see Dr. Samuel West, and with Dr. West I then again saw it. The parents were extremely anxious that something more definite should be done, and agreeing with Dr. West in his opinion that at one point in the thigh, though at one point only, there was deep-seated fluctuation, and that no harm could happen therefrom, a trocar and cannula were 
passed at that place. The instrument went down to bare bone, and there escaped a few drops of sanguineous fluid. The necessity of incision through the periosteum at once became obvious. The child was sent home, and having followed it in the evening, I made, with the help of Dr. Taylor, who administered chloroform, free incisions in both thigh and leg. Femur and tibia were alike found to be entirely denuded of periosteum throughout their whole shafts, and lying between the bones and their covering were huge blood-clots, which had to be broken up with the finger before any part of them could be removed. Hardly any fluid escaped, and the wounds showed no undue tendency to bleed. Drainage-tubes were inserted, and hot fomentations were ordered for the left limb, and also for the swelling on the right tibia, which it was deemed well to leave unopened, at any rate for a day or two, in the hope that it might subside.

The subsequent history may be told in a few words. The child at once began to improve, and the swelling of the right tibia gradually disappeared. The broken-down blood-clots were expelled by the help of syringing, and on November 13th the drainage-tubes were finally removed. Except from the immediate track of the wounds, which were perfectly closed early in December, there was never any purulent discharge.

I saw the child again on January 16th, 1883, and found it to all appearances thriving, playful, and well. The shafts of the affected bones were then of normal size, the periosteum had obviously resumed its natural position, and the only indications of the former mishief were the scars, with slight thickening of the soft parts beneath them, and inability to bring the limb to perfectly full extension. This latter defect, however, was rapidly diminishing. The beading of the ribs had gone, and the right radius, although still different from the left, was much smaller than it was. The teeth were being cut properly and the child was beginning to stand. There is no hæmorrhagic diathesis in the family. 
Although, with the complete history before us, it may now seem strange, yet it is nevertheless a fact, that the difficulties of diagnosis were in this case very considerable. Had there been anything like distinct fluctuation of the swollen leg, it is obvious that diagnosis would have been easier and more certain ; but in the absence thereof, due doubtless to the fact that blood-clot was tightly packed between periosteum and bone, no nearer diagnosis could be hazarded than that the condition was in some way or other connected with rickets. I am inclined now to think that the disease was rather scorbutic than rickety. The rearing of the child could not well have been worse, deprived as it had been of all fresh food, of that kind of food, in fact, the want of which so unquestionably induces scurvy.

If we seek to explain the hæmorrhage under the periosteum as the consequence of a rickety periostitis, we are met at once by the objection that periostitis is extremely uncommon even in the worst cases of rickets, and although it may appear extraordinary that the thickened and highly vascular state of the periosteum in severe rickets does not more frequently pass these pathological limits and involve the membrane in true inflammation, the facts are otherwise, and after the lapse of two and twenty years are still in harmony with the teaching of Sir William Jenner in his classical lectures then delivered on rickets, wherein he says: "Of Meyer's opinion that rickets is an inflammatory affection of the periosteum and endosteum I shall only say that my many examinations of rickety children after death have enabled me to lend no support to such a notion; that I have seen no sign of pre-existing inflammation of the bone or its covering, although I have carefully looked for such" ('Medical Times and Gazette,' vol. i, 1860, p. 466).

And again he writes, in a passage which bears especially on this case: "The periosteum of the whole bone is often more vascular and thicker than natural, but in the many post-mortem examinations of extreme rickets which I have 
made, I have never seen any bloody fluid as described by Guérin beneath that membrane."

The striking point, however, in this case was the mass of clotted blood surrounding the shafts of two long bones, and probably also part of the shaft of another ; but looking to the fact that the detached periosteum retained its vitality and became once more adherent to the bones, which themselves also lived, I cannot help thinking that inflammation of the periosteum was a less essential element of the pathological change than the extravasated blood. In the early stages of acute periostitis from injury, we sometimes find a blood-stained fluid between the periosteum and the bone to be rapidly followed by purulent discharge and death of the affected shaft. Here, however, there was blood-clot, the pus was very small in quantity, and all the parts have lived. Be it noted also that, although the periosteum was separated from the entire shafts, the neighbouring joints were unaffected and the cutaneous surface showed no sign of inflammation. True, the extravasation of blood, the local blood-letting, so to say, may have been the salvation of the periosteum acutely inflamed, and have preserved it from a destruction which otherwise it might not have eseaped; but may not a better explanation of the case be found in the fact that there had long been at work a cause such as that which leads to blood-extravasation in purpura and scurvy, diseases induced by lack of proper nutrition, and characterised by copious hæmorrhages and extravasations in different parts of the body.

Do other cases lend support to this doctrine? I have been able to find only one recorded case of the kind, and that was brought before the Pathological Society by $\mathbf{M r}$; Thomas Smith in 1875, and was entitled "Hæmorrhagic Periostitis of the Shafts of several of the Long Bones, with Separation of the Epiphyses" ("Transac. Patholog; Soc.,' vol. xxvii, p. 219).

The patient was a girl, æt. 23 months. She had been sackled up to three months of age, and beyond a slight VOL. LXVI. 
attack of diarrhooa had had fairly good health. There was not the least evidence of syphilitic taint, and there was but slight rickety enlargement of the ends of the ribs. The child could stand and walk alone. Eleven months before admission there were swelling and tenderness of both lower limbs commencing in the feet. This disappeared until two months before admission when the feet again began to swell. When admitted the child lay on its back with its legs stretched out and motionless. The whole of each lower limb was swollen. The hip- and knee-joints were unaffected. The temperature ranged between $99^{\circ}$ and $101.5^{\circ} \mathrm{F}$., and death took place suddenly six days after admission.

On examination the following lesions were found symmetrical as to the two sides. Complete separation of the epiphyses of the femur, and a large amount of recent blood-clot between the periosteum and the shaft, which was smooth and white. No suppuration was to be found anywhere in connection with the bones. The structures in the hip- and knee-joints were healthy. Blood was found uniformly effused through the deeper layers of many muscles of the thighs. In the leg, besides effusion into the muscles, there was similar detachment of the periosteum and separation of epiphyses from the tibia and fibula, with a large amount of extravasated blood around the denuded shafts. Crepitation could be easily felt at the shoulders, but the upper limbs were not examined. There was no disease of the abdominal viscera, but in the middle of the lower lobe of the left lung was a wedge-shaped patch of congestion as large as a chestnut, with an abrupt edge, of a reddish-purple colour. There was no history pointing to a hæmorrhagic diathesis. From the report of the discussion upon this case ('Lancet,' vol. i, 1876, p. 14) we learn that "Mr. Smith had excluded syphilis, rickets, purpura, \&c., as causal conditions, and thought the hæmorrhage was from the diseased and inflamed periosteum."

The numerous extravasations, however, which were found in other parts in Mr. Smith's case, appear to me to 
lend strong support to the theory of the scorbutic origin of the subperiosteal hæmorrhages, and to the suggestion which I have ventured to make as to the nature of the hæmorrhages in my own. The suggestion, too, gains further point from a case which, with two others, formed the text of a most instructive clinical lecture by my colleague, Dr. Cheadle, "On Three Cases of Scurvy Supervening on Rickets in Young Children " ('Lancet,' vol. ii, 1878, p. 685).

In all three cases the most prominent symptoms of scurvy had been superadded to those of rickets, and in the second of them "some hard swellings could be felt deeply seated in the flesh of each thigh, and the shafts of the long bones felt enlarged and swollen." Can there be much doubt that the enlargement of the shafts of the long bones was in that case also due to subperiosteal hæmorrhage? The other and more ordinary signs of scurvy there clearly told what unhealthy and unnatural agents had been at work, and a certain knowledge now of the physical cause of the like swollen and enlarged shafts in my own case throws light on the obscurity which in all probability involved that case no less than this. The three children referred to by Dr. Cheadle had "been fed on a scurvy diet, which comprised neither milk, nor fresh vegetables, nor fresh meat;" and it was upon a "scurvy diet" that this patient, whose history I have related, had been reared for the first nine months of its life. The rarity and interest of the pathological condition, and of the history throughout, would be my excuse for bringing an isolated case before the Society, had I not the hope that its record and consideration may help towards a surer diagnosis and better treatment in other cases like it, where the absence of swollen and bleeding gums deprives us of an all-important clue to the nature of the malady with which we have to deal. 